\title{
Second-order work in barodesy
}

\author{
Gertraud Medicus $^{1}$ (D) $\cdot$ Barbara Schneider-Muntau ${ }^{1} \cdot$ Dimitrios Kolymbas $^{1}$
}

Received: 16 January 2018 / Accepted: 23 October 2018/Published online: 18 December 2018

(C) The Author(s) 2018

\begin{abstract}
Second-order work analyses, based on elasto-plastic models, have been frequently carried out leading to the result that failure may occur before the limit yield condition is encountered. In this article, second-order work investigations are carried out with barodesy regarding standard element tests and finite element applications. In barodesy, it was shown-like in hypoplasticity and elasto-plasticity—-that second-order work may vanish at stress states inside the critical limit surface. For boundary value problems, an end-to-end shear band of vanishing second-order work marks situations, where failure is imminent.
\end{abstract}

Keywords Barodesy $\cdot$ Constitutive model $\cdot$ Finite element simulations $\cdot$ Second-order work

\section{Introduction}

Investigations, based on elasto-plastic models, have been carried out by several authors $[2-4,10,17,25,35]$ leading to the result that failure may occur before the limit yield condition is encountered. Second-order work investigations with hypoplasticity showed similar results $[2,7,14,28]$, among other things that for loose soil second-order work vanishes at stress states inside the critical limit surface.

The literature on uniqueness, stability, bifurcation and failure is vast. Stability refers to systems, as characterized by their boundary conditions, and not only to materials. In particular, the nature of tractions on the boundary plays an important role, e.g. the question whether they are dead or follower loads or not. In this article, we consider the second-order work expressed as $\operatorname{tr}(\mathbf{T} \mathbf{D})$. For symbols and notation, see Sect. 2. Many relevant citations can be found in Hill [9]. As they refer mainly to elastic solids, we cite some publications from soil mechanics.

Gertraud Medicus

Gertraud.Medicus@uibk.ac.at

Barbara Schneider-Muntau

Barbara.Schneider-muntau@uibk.ac.at

Dimitrios Kolymbas

Dimitrios.Kolymbas@uibk.ac.at

1 Division of Geotechnical and Tunnel Engineering, University of Innsbruck, Technikerstr. 13, 6020 Innsbruck, Austria
Lade [15], based on experimental results, concludes that the violation of the stability criteria of Hill, $\operatorname{tr}\left(\mathbf{T}^{\circ} \mathbf{D}\right) \geq 0$, and Drucker, $\operatorname{tr}\left(\stackrel{\mathbf{T}}{\mathbf{D}}^{\mathrm{pl}}\right) \geq 0$, does not necessarily evoke an observable collapse of the sample.

Nova [29] investigated the controllability of element tests of soils obeying the constitutive law $\mathbf{D}=\mathcal{C} \mathbf{T}$, with $\mathcal{C}$ being the fourth-order compliance matrix. As loading program, he denotes the prescription of $n$ components of $\mathbf{D}$ (or linear combinations thereof) and the remaining $6-n$ components of $\mathbf{T}$ (or linear combinations thereof), with $0 \leq n \leq 6$. The response to this loading program consists of the corresponding $6-n$ components of $\stackrel{\circ}{\mathbf{D}}$ and the remaining $n$ components of $\stackrel{\circ}{\mathbf{T}}$. He concludes that the constitutive relation determines a unique response, if the symmetric matrix $\mathcal{C}^{\mathrm{s}}$ is positive definite:

$\mathbf{D} \mathcal{C} \mathbf{D}>0$

or, equivalently, if the 'second-order work' $W_{2}$ is positive:

$$
\begin{aligned}
W_{2} & =\operatorname{tr}(\stackrel{\circ}{\mathbf{T} D}) \\
& =\stackrel{\circ}{T}_{11} D_{11}+\stackrel{\circ}{T}_{22} D_{22}+\stackrel{\circ}{T}_{33} D_{33}+2 \stackrel{\circ}{T}_{12} D_{12}+2 \stackrel{\circ}{T}_{23} D_{23} \\
& +2 \stackrel{\circ}{T}_{13} D_{13}>0 .
\end{aligned}
$$

The unique invertibility (in the sense of unique response to any loading program) was called by Nova 'controllability'. This term is, however, somehow misleading, as it can be easily conceived as the condition for obtaining a 
unique deformation of a sample by application of boundary tractions and displacements (in the sense that the deformation of a body is controlled by the boundary tractions and displacements). Such deformation is in many cases expected to be homogeneous, the corresponding tests are then called 'element tests'. The unique solution of a boundary value problem with prescribed boundary displacements does, however, not follow from $W_{2}>0$ but from another condition, firstly derived by Hill [9], as shown here in a simplified form: we consider the velocity field $\mathbf{v}$ as the solution of a boundary value problem and investigate whether this solution is unique. Assume that there exists also another solution $\overline{\mathbf{v}} \neq \mathbf{v}$. Denoting differences by a prime, e.g. $\mathbf{v}^{\prime}=\mathbf{v}-\overline{\mathbf{v}}$, we observe that $\mathbf{v}^{\prime}$ vanishes at the boundary. The equilibrium equation reads $\nabla \cdot \mathbf{T}=\mathbf{0}$, and continued equilibrium reads $\nabla \cdot \dot{\mathbf{T}}=\mathbf{0}$. The same equations hold also for the stress difference $\mathbf{T}^{\prime}:=\mathbf{T}-\overline{\mathbf{T}}: \nabla \cdot \mathbf{T}^{\prime}=\mathbf{0}$ and $\nabla \cdot \dot{\mathbf{T}}^{\prime}=\mathbf{0}$. We now consider the integral $I:=\int_{V} \nabla \cdot\left(\dot{\mathbf{T}}^{\prime} \mathbf{v}^{\prime}\right) \mathrm{d} V$ and apply the theorem of Gauss. We thus obtain that this integral vanishes:

$\int_{V} \nabla \cdot\left(\dot{\mathbf{T}}^{\prime} \mathbf{v}^{\prime}\right) \mathrm{d} V=\int_{S} \mathbf{T}^{\prime} \mathbf{v}^{\prime} \cdot \mathbf{n} \mathrm{d} S=0$,

because $\mathbf{v}^{\prime}=\mathbf{0}$ on the surface $S$. Further,

$$
\begin{aligned}
I & =\int_{V} \nabla \cdot\left(\dot{\mathbf{T}}^{\prime} \mathbf{v}^{\prime}\right) \mathrm{d} V=\int_{V} \dot{\mathbf{T}}^{\prime} \cdot \nabla \mathbf{v}^{\prime} \mathrm{d} V+\int_{V} \mathbf{v}^{\prime} \nabla \cdot \dot{\mathbf{T}}^{\prime} \mathrm{d} V \\
& =0
\end{aligned}
$$

The second integral on the right-hand side vanishes due to continued equilibrium. Thus, for non-uniqueness must hold:

$$
\int_{V} \dot{\mathbf{T}}^{\prime} \cdot \nabla \mathbf{v}^{\prime} \mathrm{d} V \equiv \int_{V} \dot{\mathbf{T}}^{\prime} \cdot \mathbf{D}^{\prime} \mathrm{d} V=0,
$$

which is impossible if $\dot{\mathbf{T}}^{\prime} \cdot \mathbf{D}^{\prime}>0$ holds everywhere [the notation $\dot{\mathbf{T}}^{\prime} \cdot \mathbf{D}^{\prime}$ denotes the same as $\operatorname{tr}\left(\dot{\mathbf{T}}^{\prime} \mathbf{D}^{\prime}\right)$ ]. Hence the condition $C_{1}$

$$
\operatorname{tr}\left(\dot{\mathbf{T}}^{\prime} \mathbf{D}^{\prime}\right)>0
$$

implies uniqueness. For the special case $\overline{\mathbf{v}}=\mathbf{0}$ we have: $\operatorname{tr}\left(\dot{\mathbf{T}}^{\prime} \mathbf{D}^{\prime}\right)=\operatorname{tr}(\dot{\mathbf{T}} \mathbf{D})$. Hence,

$$
\operatorname{tr}\left(\dot{\mathbf{T}}^{\prime} \mathbf{D}^{\prime}\right)>0 \leadsto \operatorname{tr}(\dot{\mathbf{T}} \mathbf{D})>0
$$

Thus we have

$$
C_{1} \rightsquigarrow \text { uniqueness }
$$

and

$$
C_{1} \rightsquigarrow \operatorname{tr}(\dot{\mathbf{T D}})>0 .
$$

However, the statement that $\operatorname{tr}(\dot{\mathbf{T D}})>0$ implies uniqueness cannot be generally inferred, e.g. uniqueness is implied if the material is incrementally linear.

Negative second-order work denotes softening, i.e. the tangential stiffness has at least one negative eigenvalue. For some static boundary conditions of dead loads, this implies increasing in kinetic energy and thus collapse. In fact, Nicot et al. [26] correlate vanishing second-order work with increase of kinetic energy and corresponding failure.

\section{Symbols and notation}

We use the symbolic notation for Cauchy effective stress $\mathbf{T}$ and stretching $\mathbf{D}$. In the figures, the more familiar symbol $\sigma_{i}$ instead of $T_{i}$ is used for the principal stresses. Normal stresses are defined negative for compression. Tensors are written in bold capital letters (e.g. $\mathbf{X}$ ). $|\mathbf{X}|:=\sqrt{\operatorname{tr} \mathbf{X}^{2}}$ is the Euclidean norm of $\mathbf{X}, \operatorname{tr} \mathbf{X}$ is the sum of the diagonal components of $\mathbf{X}$. The superscript 0 marks a normalized tensor, i.e. $\mathbf{X}^{0}=\mathbf{X} /|\mathbf{X}|$. 1 denotes the second-order unit tensor. Stresses are considered as effective ones, the normally used dash is omitted. The stretching tensor $\mathbf{D}$ is the symmetric part of the velocity gradient. Stretching $\mathbf{D}$ is only approximately equivalent to the strain rate $\dot{\boldsymbol{\varepsilon}}$. For rectilinear extensions however, $\mathbf{D}$ equals $\dot{\boldsymbol{\varepsilon}}$, considering the logarithmic strain $\varepsilon$. $p:=-\frac{1}{3} \operatorname{tr} \mathbf{T}$ is the mean effective stress, $\varepsilon_{\mathrm{vol}}=\operatorname{tr} \varepsilon$ is the volumetric strain. For compressive strain, $\varepsilon_{i}$ is defined negative.

The deviatoric stress is written as $q=-\left(\sigma_{1}-\sigma_{3}\right)$ and the deviatoric strain reads $\varepsilon_{q}=-2 / 3 \cdot\left(\varepsilon_{1}-\varepsilon_{3}\right)$ for axisymmetric conditions.

Note that several definitions for dilatancy can be found. In barodesy is used $\delta:=\operatorname{tr} \mathbf{D}^{0}=\dot{\varepsilon}_{\mathrm{vol}} /|\dot{\boldsymbol{\varepsilon}}|$. A common definition of the angle of dilatancy $\psi$ for axisymmetric triaxial compression, i.e. $\dot{\varepsilon}_{1}<0$, is, see e.g. [23]:

$$
\frac{\dot{\varepsilon}_{\mathrm{vol}}}{\dot{\varepsilon}_{\mathrm{q}}}=\frac{-6 \sin \psi}{3-\sin \psi} \text {. }
$$

This ratio of volumetric to deviatoric strain rate can be expressed in dependence of $\delta$, (for $\delta>0$ ) as:

$\frac{\dot{\varepsilon}_{\mathrm{vol}}}{\dot{\varepsilon}_{\mathrm{q}}}=\frac{-3 \delta}{\sqrt{6-2 \delta^{2}}}$.

From Eqs. 10 and 11 follows:

$\delta=\frac{2 \sqrt{2} \sin \psi}{\sqrt{3-2 \sin \psi+3 \sin ^{2} \psi}}$. 


\section{Barodesy}

Similar to hypoplasticity, barodesy ${ }^{1}$ is a constitutive relation of the form $\stackrel{\circ}{\mathbf{T}}=\mathbf{h}(\mathbf{T}, \mathbf{D}, e)$, which is based on the asymptotic behaviour of soil $[12,13,20]$. The general form of the barodetic constitutive relation is:

$\stackrel{\circ}{\mathbf{T}}=h \cdot\left(f \mathbf{R}^{0}+g \mathbf{T}^{0}\right) \cdot|\mathbf{D}|$

$\mathbf{R}^{0}$ and $\mathbf{T}^{0}$ are the normalized tensors of proportional stress paths $\mathbf{R}$ and stress $\mathbf{T}$, respectively. The tensor $\mathbf{R}$ depends on $\mathbf{D}$, and the relation $\mathbf{R}(\mathbf{D})=-\exp \left(\alpha \mathbf{D}^{0}\right)$ includes a stress-dilatancy relation [21], with $\alpha$ as a scalar quantity. The scalar quantities $h, f$ and $g$ depend on the actual stress level, the actual void ratio $e$ and a stress-dependent critical void ratio $e_{\mathrm{c}}$ and, thus describe barotropy and pyknotropy. ${ }^{2}$ Appendix 1 summarizes all equations of barodesy. Regarding second-order work, we have to check whether the expression

$$
\operatorname{tr}(\mathbf{T} \mathbf{D})=h \cdot\left(f \cdot \operatorname{tr}\left(\mathbf{R}^{0} \mathbf{D}\right)+g \cdot \operatorname{tr}\left(\mathbf{T}^{0} \mathbf{D}\right)\right) \cdot|\mathbf{D}|
$$

can become negative or equal to zero. In barodesy, the second-order work is zero when $Y$ (Eq. 15) is zero:

$Y=\frac{\operatorname{tr}(\stackrel{\mathbf{T} D}{\mathbf{D}})}{h \cdot g \cdot|\mathbf{D}|^{2}}:=\frac{f}{g} \operatorname{tr}\left(\mathbf{R}^{0} \mathbf{D}^{0}\right)+\operatorname{tr}\left(\mathbf{T}^{0} \mathbf{D}^{0}\right)=0$.

The variables $f, g$ and $\mathbf{R}^{0}$ depend on $\mathbf{D}^{0}$. We therefore may rewrite equation 15 as:

$k\left(\mathbf{D}^{0}\right)+\operatorname{tr}\left(\mathbf{T}^{0} \mathbf{D}^{0}\right)=0$.

To determine the boundary of the region with $W_{2}>0$ in stress space, we consider a stress state $\mathbf{T}$ and ask whether there is a $\mathbf{D}$ such that Eq. (16) be just fulfilled. 'Just fulfilled' means that there is only one solution $\hat{\mathbf{D}}$. This implies

$$
\begin{aligned}
& k\left(\hat{\mathbf{D}}^{0}\right)+\operatorname{tr}\left(\mathbf{T}^{0} \hat{\mathbf{D}}^{0}\right)=0 \text { and } k\left(\mathbf{D}^{0}\right)+\operatorname{tr}\left(\mathbf{T}^{0} \mathbf{D}^{0}\right)<0 \\
& \quad \text { for } \mathbf{D}^{0} \neq \hat{\mathbf{D}}^{0} .
\end{aligned}
$$

Equation (16) introduces a relation between $\mathbf{D}^{0}$ and $\mathbf{T}^{0}$, that is not necessarily unique. However, the additional requirement (17) imposes uniqueness and, thus, establishes a function

\footnotetext{
${ }^{1}$ Hypoplasticity and barodesy are constitutive models which do not use the standard notions of elasto-plastic models (such as elastic region, yield function, flow function, ...). Instead, the effective co-

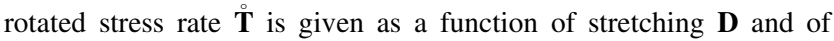
effective stress $\mathbf{T}$, optionally complemented by further variables, as the void ratio $e$

2 In this article, the simulations are carried out with barodesy for clay. All equations and a detailed description can be found in the open access article by Medicus and Fellin [20].
}

$\hat{\mathbf{D}}^{0}=\mathbf{h}\left(\mathbf{T}^{0}\right)$

As in Eq. $18 \mathbf{T}^{0}$ is a function of $\hat{\mathbf{D}}^{0}$, it can be written as

$\mathbf{T}^{0}=a \cdot \mathbf{1}+b \cdot \hat{\mathbf{D}}^{0}+c \cdot \hat{\mathbf{D}^{0}}$,

according to the theorem of Cayley-Hamilton. The scalars $a, b$ and $c$ depend on the invariants of $\hat{\mathbf{D}}^{0}$. Equation 19 is only valid for vanishing second-order work. It therefore follows for $W_{2}=0$, that (for isotropic materials) $\mathbf{T}^{0}$ and $\hat{\mathbf{D}}^{0}$ are coaxial.

As in Sect. 4 only rectilinear extensions are examined, the co-rotational, objective stress rate $\mathbf{T}^{\circ}$ coincides with $\dot{\mathbf{T}}$. This follows from $\stackrel{\circ}{\mathbf{T}}=\dot{\mathbf{T}}+\mathbf{T W}-\mathbf{W T}$ and $\mathbf{W}=\mathbf{0}$. In general cases (e.g. the finite element applications in Sect. 5), we do consider the Zaremba-Jaumann rate $\stackrel{\mathbf{T}}{\text {. }}$.

Several rectilinear deformations represented by the principal stresses $T_{1}, T_{2}, T_{3}$ will be numerically examined as to whether there can be found $\mathbf{D}^{0}$-tensors such that $\operatorname{tr}\left(\dot{\mathbf{T}} \mathbf{D}^{0}\right)=0$. The boundary of the region in stress space with $\operatorname{tr}\left(\dot{\mathbf{T}} \mathbf{D}^{0}\right)>0$ is the surface of vanishing second-order work.

\section{Element tests}

We investigate the second-order work for specific loading paths in standard element tests (Sects. 4.1-4.2) and give a more general perspective in Sect. 4.3.

\subsection{Undrained triaxial test}

The undrained triaxial test is an illustrative example to explain vanishing second-order work inside the critical stress surface. As it is a rectilinear extension, we set $\mathbf{D}=\dot{\boldsymbol{\varepsilon}}$. For an undrained test applies $\operatorname{tr} \mathbf{D}=0$ (i.e. $\dot{\varepsilon}_{\mathrm{vol}}=\dot{\varepsilon}_{1}+2 \dot{\varepsilon}_{2}=0$ ) and therefore $\dot{\varepsilon}_{2}=-1 / 2 \cdot \dot{\varepsilon}_{1}$. $\operatorname{tr}(\dot{\mathbf{T} D})=\dot{T}_{1} \cdot \dot{\varepsilon}_{1}+2 \cdot \dot{T}_{2} \cdot \dot{\varepsilon}_{2}=\dot{T}_{1} \cdot \dot{\varepsilon}_{1}-\dot{T}_{2} \cdot \dot{\varepsilon}_{1}=-\dot{q} \cdot \dot{\varepsilon}_{1}$.

From Eq. 20 follows $\operatorname{tr}(\dot{\mathbf{T} D})=0$ for $\dot{q}=0$, cf. Fig. 1 . Tests controlled with dead loads are not possible beyond the maximum of $q\left(\dot{q}=0\right.$ and $\left.\dot{\varepsilon}_{1} \neq 0\right)$. The experimental results in Fig. 1a refer to London clay by Gasparre [6], in Fig. 1b normally consolidated London clay samples are simulated with barodesy [20], cf. Table 1 for parameters. The solid line marks the points of vanishing second-order work, the dotdashed line is the critical state line. The maximum of $q(\dot{q}=0$ and $\operatorname{tr}(\dot{\mathbf{T} D})=0$ ) is clearly visible. Note that the mobilized friction angle at the maximum of $q$ is lower than at critical state (marked with the crosses + in Fig. 1). 
(a)

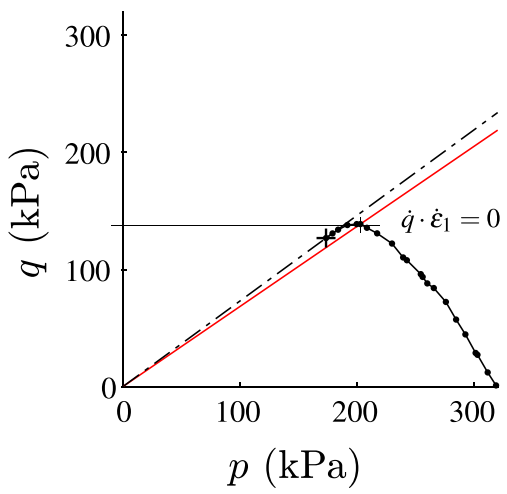

(b)

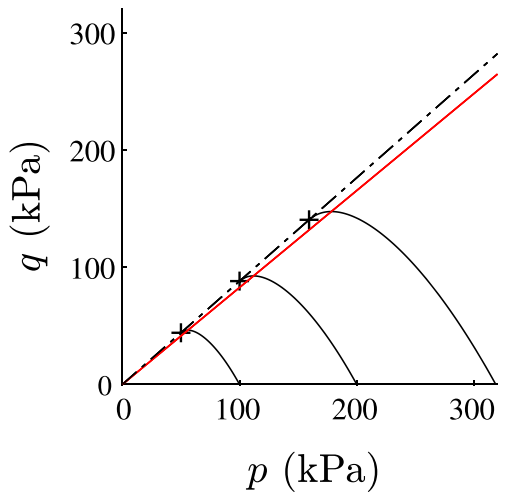

Fig. 1 Normally consolidated CU tests: at the maximum of $q(\dot{q}=0$ and $\left.\dot{\varepsilon}_{1} \neq 0\right), \operatorname{tr}(\dot{\mathbf{T} D})$ vanishes. The crosses + mark the critical stress states. The solid line is the locus of vanishing second-order work, the dot-dashed line is the critical state line, i.e. $q=M \cdot p$ with $M=$ $6 \sin \varphi_{\mathrm{c}} /\left(3-\sin \varphi_{\mathrm{c}}\right)$ for triaxial axisymmetric compression. The experimental results in a refer to London clay by Gasparre [6] (test r10nc), in b normally consolidated London clay is simulated with barodesy [20]

Table 1 Critical state soil mechanics parameters used for the calibration of barodesy

\begin{tabular}{llllll}
\hline Material & $\varphi_{\mathrm{c}}$ & $N$ & $\lambda^{*}$ & $\kappa^{*}$ & Source \\
\hline London clay & $22.6^{\circ}$ & 1.375 & 0.11 & 0.016 & Mašín [18] \\
Weald clay & $24^{\circ}$ & 0.8 & 0.059 & 0.018 & Mašín [19] \\
\hline
\end{tabular}

In Appendix 2, we add the drained triaxial test as an illustrative example to investigate second-order work in barodesy.

\subsection{Non-conventional drained triaxial tests}

We consider drained triaxial tests with reduction of $p$ at $q=$ const. For normally consolidated Weald clay (for parameters see Table 1) we set $p_{\text {ini }}=50 \mathrm{kPa}$, $p_{\text {ini }}=100 \mathrm{kPa}$ and $p_{\text {ini }}=200 \mathrm{kPa}$. The tests start as conventional drained triaxial tests and at $\sigma_{1}=1 / K_{0} \cdot \sigma_{2}$ the mean effective stress $p$ is decreased by increasing the pore pressure, cf. similar experiments by Lade [15] and simulations by Wan and Pinheiro [34]. A reduction in the mean stress is obtained e.g. in the case of an excavation [8]. For the tests in Fig. 2a, the deviatoric stress remains constant $(q=75 \mathrm{kPa}$ for test A, $q=150 \mathrm{kPa}$ for test $\mathrm{B}$, $q=300 \mathrm{kPa}$ for test $\mathrm{C}$ ), hence $\dot{q}=0$. The second-order work according to equation 37 simplifies thus to $\operatorname{tr}(\dot{\mathbf{T} D})=\dot{p} \cdot \dot{\varepsilon}_{\mathrm{vol}}$. With decreasing $p$, i.e. $\dot{p} \neq 0$, the secondorder work vanishes for this specific loading path at $\dot{\varepsilon}_{\mathrm{vol}}=0$. Simulations with barodesy show that in the nonconventional drained triaxial tests of Fig. 2, the secondorder work vanishes inside the critical limit surface.

Figure 2a shows the stress paths of the non-conventional triaxial tests. The stress states with $\operatorname{tr}(\dot{\mathbf{T} D})=0$ are marked with circles (o) and connected with a line. In Fig. 2b, c the solid line shows the volumetric strain and the dashed line the second-order work of test A. It is visible that secondorder work is zero at the local maximum of $\varepsilon_{\mathrm{vol}}$, i.e. $\dot{\varepsilon}_{\mathrm{vol}}=0$, which has experimentally been confirmed: a sudden collapse is reported to occur [3, 17] at the local maximum of volumetric strain. The mobilized friction angle at $\operatorname{tr}(\dot{\mathbf{T} D})=0$ is smaller than the mobilized friction angle at critical state, cf. Fig. 2a.

\subsection{Investigations in the deviatoric plane}

The following analysis has been carried out numerically. We consider the deviatoric plane $\operatorname{tr} \mathbf{T}=-500 \mathrm{kPa}=$ const. in the principal stress space spanned by $T_{1}, T_{2}, T_{3}$ and we search for the boundary of the region where $\operatorname{tr}(\dot{\mathbf{T} D})>0$. We examine stress rays starting from the hydrostatic axis $T_{1}=T_{2}=T_{3}$. On each ray, we step forward with small increments of deviatoric stress. At each step, we check whether there are $\mathbf{D}$ tensors such that the condition $\operatorname{tr}(\dot{\mathbf{T} D})=0$ is fulfilled.

To this end, it is sufficient to check tensors $\mathbf{D}^{0}$, coaxial to $\mathbf{T}$, distributed in all directions of the space $D_{1}, D_{2}, D_{3}$, with the magnitude $|\mathbf{D}|=1$, the polar angle $0<\theta<\pi$, and azimuth angle $0<\phi<2 \pi$. The principal values of $\mathbf{D}$ are:

$$
\begin{aligned}
& D_{1}=\sin \theta \cdot \cos \phi \\
& D_{2}=\sin \theta \cdot \sin \phi \\
& D_{3}=\cos \theta
\end{aligned}
$$

We vary $\theta$ and $\phi$ independently on each stress ray for every step and search for minimum values of second-order work. As soon as $\operatorname{tr}(\dot{\mathbf{T} D})=0$ is encountered, the stress state $\mathbf{T}$ belongs to the searched boundary. 
(a)

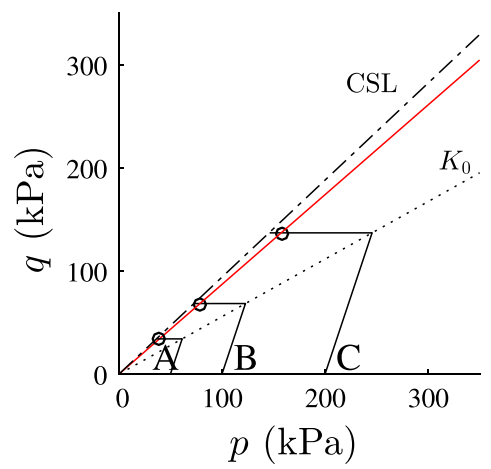

(b)

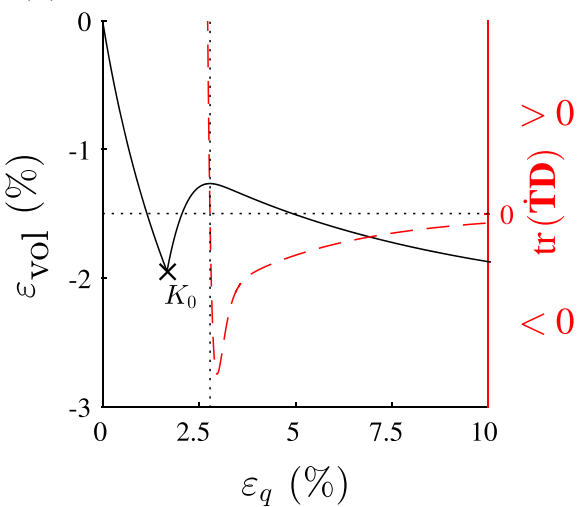

(c)

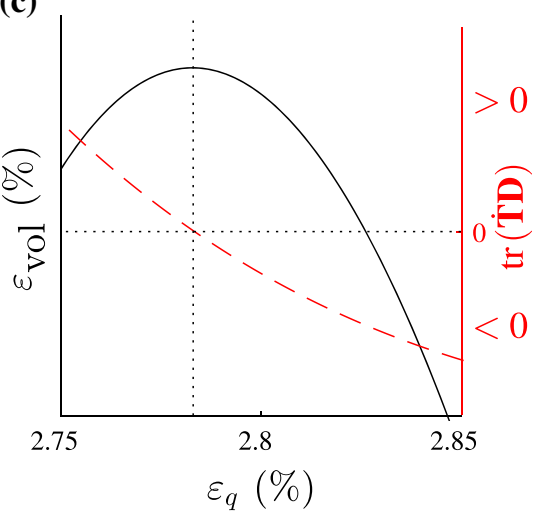

Fig. 2 Simulations of non-conventional drained triaxial tests of Weald clay ( $\varphi_{\mathrm{c}}=24^{\circ}$, see Table 1 for parameters) with barodesy: all samples are initially normally consolidated with $50 \mathrm{kPa}, 100 \mathrm{kPa}$ and $200 \mathrm{kPa}$. In a stress paths of tests A, B and C are displayed and stress states with $\operatorname{tr}(\dot{\mathbf{T D}})=0$ are marked with circle, in $\mathbf{b}$ the volumetric behaviour (solid line) and $\operatorname{tr}(\dot{\mathbf{T} D})$ (broken line) of test A are shown. The $K_{0}$ state is marked in $\mathbf{a}$ and $\mathbf{b}$. c Detail of $\mathbf{b}$ where it is visible that $W_{2}=0$ at a local maximum of $\dot{\varepsilon}_{\mathrm{vol}}$

The Mohr-Coulomb yield locus in the deviatoric plane corresponds to a hexagon and the mobilized friction angle $\varphi_{\mathrm{m}}$ reads $^{3}$ :

$\sin \varphi_{\mathrm{m}}=\frac{T_{\min }-T_{\max }}{T_{\min }+T_{\max }}$

In barodesy, the cone of critical stress states practically coincides with the locus according to Matsuoka-Nakai $[5,21]$ and is characterized through Eq. 25:

$\frac{\left(\sigma_{1}+\sigma_{2}+\sigma_{3}\right)\left(\sigma_{1} \sigma_{2}+\sigma_{1} \sigma_{3}+\sigma_{2} \sigma_{3}\right)}{\sigma_{1} \sigma_{2} \sigma_{3}}=\frac{9-\sin ^{2} \varphi_{\mathrm{c}}}{1-\sin ^{2} \varphi_{\mathrm{c}}}$.

In Fig. 3, vanishing second-order work is investigated with barodesy for Weald clay $\left(\varphi_{\mathrm{c}}=24^{\circ}\right)$. The following results are obtained:

- For normally consolidated $\operatorname{soil}^{4}\left(\mathrm{OCR}=1\right.$ and $\left.e>e_{\mathrm{c}}\right)$ this cone lies inside the cone of critical stress states (Eq. 25).

- For $e=e_{\mathrm{c}}\left(p_{\mathrm{e}} / p=2\right.$ respectively), the cone of critical states and the cone of $\operatorname{tr}(\dot{\mathbf{T} D})=0$ differ only slightly: However, the cone of vanishing second-order work lies inside the cone of critical stress states.

\footnotetext{
${ }^{3}$ In this article, the mobilized friction angle when second-order work vanishes is denoted as $\varphi_{W_{2}}$.

${ }^{4}$ It is common to define the overconsolidation ratio $\left(\mathrm{OCR}=p_{\mathrm{e}} / p\right)$ by means of the so-called Hvorslev's equivalent consolidation pressure $p_{\mathrm{e}}=\exp \left(\frac{N-\ln (1+e)}{\lambda^{*}}\right)$, divided by the actual mean stress $p$. $p_{\mathrm{e}}$ is the value of mean stress on the isotropic normal consolidation line which refers to the current specific volume $(1+e)$. If $p / p_{\mathrm{e}}=$ const in a deviatoric plane ( $p=$ const), then the void ratio $e$ is constant.
}

- For highly overconsolidated soil $e<e_{\mathrm{c}}(\mathrm{OCR}=6)$, the cone with $\operatorname{tr}(\dot{\mathbf{T} D})=0$ lies outside the cone of critical stress states.

In Fig. 5a-c, stress locations in the deviatoric plane $(\operatorname{tr} \mathbf{T}=$ const $)$, characterized by the Lode angle $\alpha_{\sigma}$ (Eq. 26), are further investigated. The Lode angle $\alpha_{\sigma}$ is defined as follows:

$$
\begin{aligned}
& \alpha_{\sigma}=\frac{1}{3} \arcsin \frac{-3 \sqrt{6} \operatorname{det} \mathbf{T}^{*}}{\left|\mathbf{T}^{*}\right|^{3}} \\
& \text { with } \quad \mathbf{T}^{*}=\mathbf{T}-\frac{1}{3} \cdot \operatorname{tr} \mathbf{T} \cdot \mathbf{1}
\end{aligned}
$$

$\alpha_{\sigma}=30^{\circ}$ holds for triaxial compression and $\alpha_{\sigma}=-30^{\circ}$ holds for triaxial extension. The angle $\beta$ between the directions of stress $\mathbf{T}^{0}$ and stretching $\mathbf{D}^{0}$ reads, cf. [7]:

$\cos \beta=\mathbf{T}^{0} \cdot \mathbf{D}^{0}=\operatorname{tr}\left(\mathbf{T}^{0} \mathbf{D}^{0}\right)$

For the undrained triaxial tests (with a prescribed D, i.e. $D_{1}=-1, D_{2}=D_{3}=0.5$ and $\operatorname{tr} \mathbf{D}^{0}=0$ ) in Fig. $1 \mathrm{~b} \beta$ is approximately $63.6^{\circ}$ and the mobilized friction angle is $\varphi_{W_{2}} \approx 21.3^{\circ}$, when $W_{2}=0$. A variation of $\mathbf{D}$ according to Eqs. 21-23 in order to find vanishing values of $W_{2}$ results in a slightly lower mobilized friction angle of $\varphi_{W_{2}}=21.1^{\circ}$. This variation was carried out at axisymmetric stress states. The critical friction angle of London clay is $22.6^{\circ}$.

For the non-conventional triaxial tests in Fig. $2, \beta$ is approximately $86.4^{\circ}$ and the mobilized friction angle $\varphi_{W_{2}}$ is approximately $22.340^{\circ}$, which is also lower than the critical friction angle of Weald clay with $24^{\circ}$. A variation of $\mathbf{D}$ according to Eqs. 21-23 in order to find vanishing values of $W_{2}$ results in a slightly lower mobilized friction angle of $\varphi_{W_{2}}=22.336^{\circ}$. 


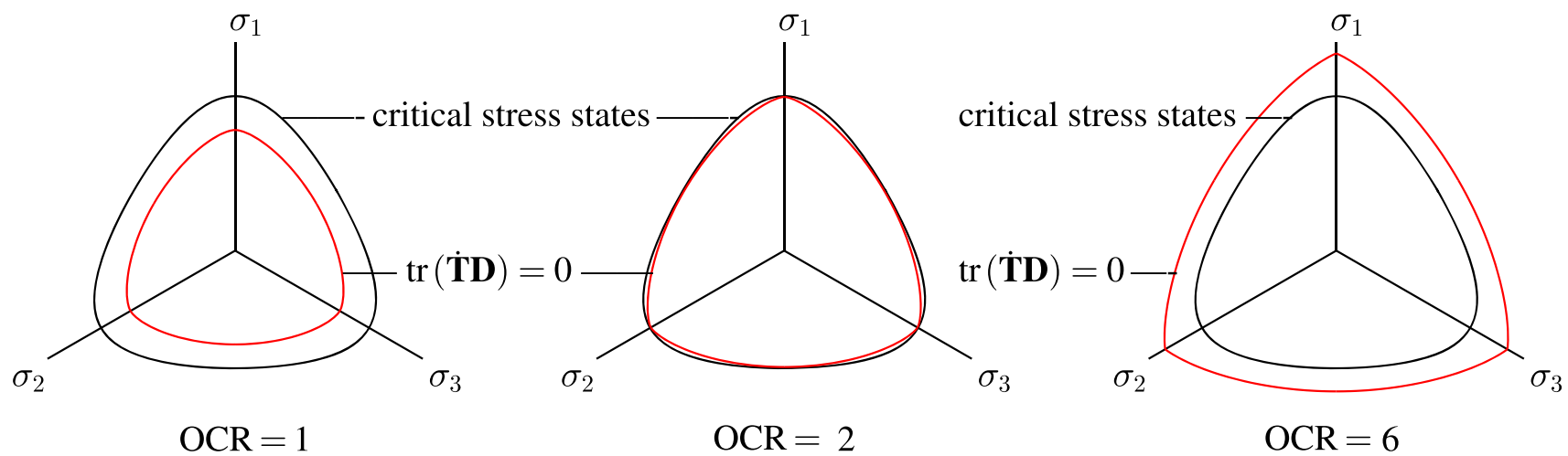

Fig. 3 Surfaces of vanishing second-order work in the deviatoric plane. Obtained with barodesy [20] for various OCR-values. The critical state surface is also shown

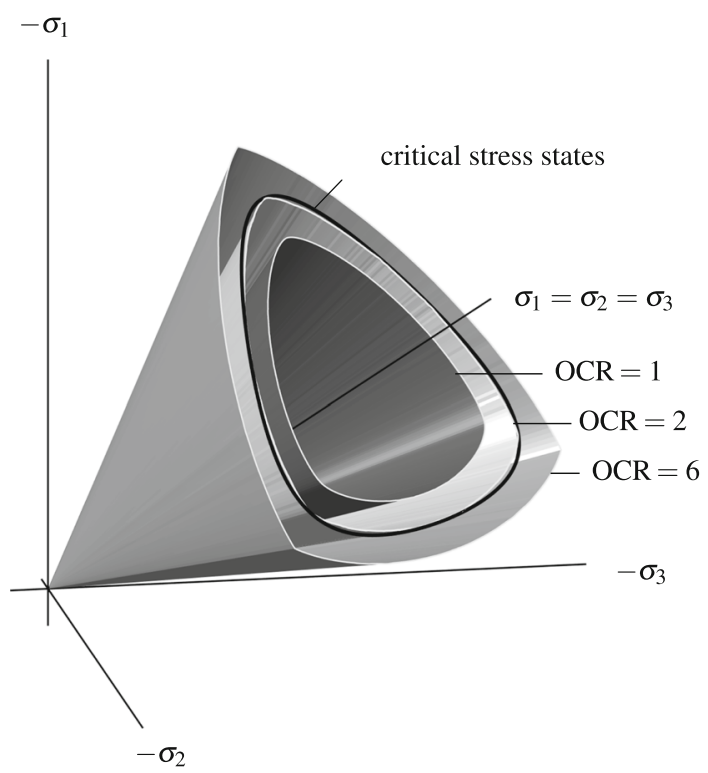

Fig. 4 In barodesy, $\operatorname{tr}(\dot{\mathbf{T} D})=0$ is described by a cone. A $3 \mathrm{D}$ representation of surfaces formed by $\operatorname{tr}(\dot{\mathbf{T} D})=0$ for $\mathrm{OCR}=1$, $\mathrm{OCR}=2$ and $\mathrm{OCR}=6$ according to Fig. 3 is shown. The critical stress surface of barodesy (Eq. 25) is added for $\operatorname{tr} \mathbf{T}=-500 \mathrm{kPa}$. In this plot, Weald clay is simulated with barodesy [20]

Figures 4 and 5 give a more general view of the vanishing second-order work locus:

- In Fig. 4 a 3D representation of surfaces formed by $\operatorname{tr}(\dot{\mathbf{T} D})=0$ for three different overconsolidation ratios $(\mathrm{OCR}=1, \quad \mathrm{OCR}=2$ and $\mathrm{OCR}=6$ according to Fig. 3) is shown. The cross section of the critical stress surface of barodesy (Eq. 25) with the deviatoric plane $\operatorname{tr} \mathbf{T}=-500 \mathrm{kPa}$ is added.

- Figure 5a shows the mobilized friction angles $\varphi_{W_{2}}$ (obtained with $\sin \varphi_{\mathrm{m}}=\frac{T_{\min }-T_{\max }}{T_{\min }+T_{\max }}$ ) along the $\operatorname{tr}(\dot{\mathbf{T} D})=0$ locus versus $\alpha_{\sigma}$. For normally consolidated samples $(\mathrm{OCR}=1)$, the minimum mobilized friction angle is $\varphi_{W_{2}} \approx 18^{\circ}$, which is only $3^{\circ}$ higher than the mobilized friction angle under oedometric conditions estimated with Jáky's relation. ${ }^{5}$ Similar results have been obtained with hypoplasticity [7]. For the OCR $=2$, the cone of vanishing second-order work lies slightly inside the cone of critical states, cf. Fig. 5a. For highly overconsolidated soil, $\varphi_{W_{2}}$ is higher than $\varphi_{W_{2}}$ of the critical stress surface, cf. Fig. 5a.

- Furthermore for OCR $=1$ the angle $\beta$ between normalized stress $\mathbf{T}^{0}$ and stretching $\mathbf{D}^{0}$ according to Eq. 27 is $63^{\circ}<\beta<69^{\circ}$, cf. Fig. $5 \mathrm{~b}$, the lower the void ratio (the higher the OCR), the higher the angle $\beta$. For highly overconsolidated soil, the angle $\beta\left(77^{\circ}<\beta<82^{\circ}\right)$ in Fig. $5 \mathrm{~b}$ is higher than for slightly overconsolidated or normally consolidated soil.

- Figure 5c shows the dilatancy $\delta=\operatorname{tr} \mathbf{D}^{0}$ in dependence of the Lode angle $\alpha_{\sigma}$. For normally consolidated clay (OCR = 1), the behaviour is slightly contractant $\left(\operatorname{tr} \mathbf{D}^{0} \approx-0.2\right)$. Note that $\operatorname{tr} \mathbf{D}^{0}=0$ describes isochoric deformation and $\operatorname{tr} \mathbf{D}^{0}=-1$ applies for oedometric compression. In addition, the angle of dilatancy $\psi$ is also shown in Fig. 5c. ${ }^{6}$ For an overconsolidation ratio of 2 , clay is slightly dilatant $\left(\operatorname{tr} \mathbf{D}^{0} \approx 0.1\right)$, for overconsolidated samples $(\mathrm{OCR}=6), \operatorname{tr} \mathbf{D}^{0} \approx 0.4$, cf. Fig. 5c. Arthur et al. [1] (cited in [33]) report that the angles of dilatancy $\psi$ in the shear plane in dense biaxial tests with sand were about $9^{\circ} \leq \psi \leq 30^{\circ}$. Simulations of overconsolidated samples $(\mathrm{OCR}=2 \ldots 6)$ with barodesy result in angles of dilatancy in the range of $3^{\circ}<\psi<14^{\circ}$, see

${ }^{5}$ From the earth pressure coefficient at rest $K_{0}=1-\sin \varphi_{\mathrm{c}}=$ $\frac{1-\sin \varphi_{\mathrm{m}}}{1+\sin \varphi_{\mathrm{m}}}$ we obtain with $\varphi_{\mathrm{c}}=24^{\circ}$ the mobilized friction angle under oedometric conditions $\varphi_{W_{2}}=\arcsin \frac{\sin \varphi_{\mathrm{c}}}{2-\sin \varphi_{\mathrm{c}}} \approx 15^{\circ}$.

${ }^{6}$ Note that the angle of dilatancy $\psi$ in Fig. 5c strictly applies for axisymmetric compression (i.e. $\alpha_{\sigma}=30^{\circ}$ ) only. Experimental studies by Nakai [24] showed that $0<\alpha_{\sigma}<15^{\circ}$ for plane strain conditions. These findings correspond to results obtained with barodesy [21]. 
(a)

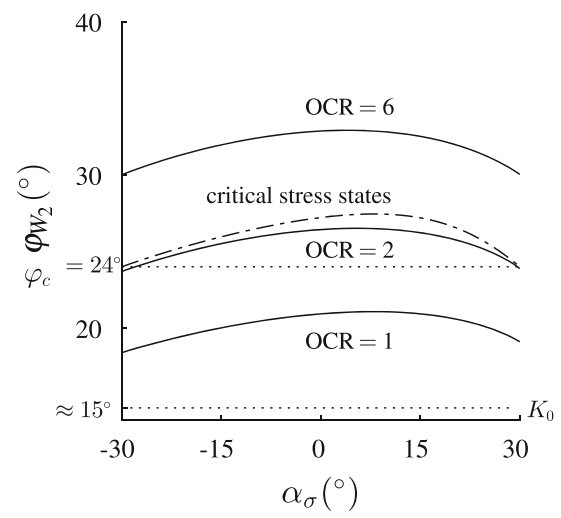

(b)

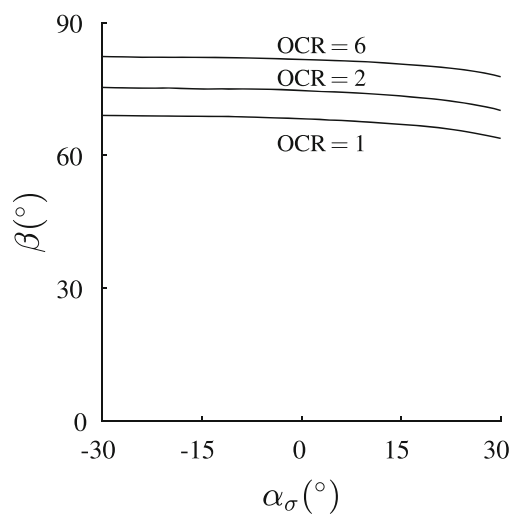

(c)

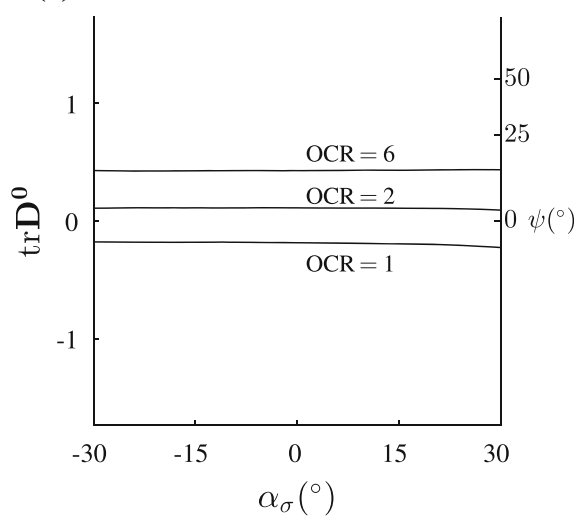

Fig. 5 In $\mathbf{a} \varphi_{W_{2}}$ according to Eq. 24 is shown for the different overconsolidation ratios, $\mathbf{b} \beta-\alpha_{\sigma}$ plot, $\mathbf{c} \operatorname{tr} \mathbf{D}^{0}-\alpha_{\sigma}$ plot. In this plot, Weald clay is simulated with barodesy [20]

Fig. 5c. As in this article, clay samples with arbitrary overconsolidation ratios are investigated, only a qualitative comparison of the values for $\psi$ is possible.

Attention should be paid to normally consolidated/slightly overconsolidated soils, where second-order work may vanish inside the critical stress surface. The results provide a basis for finite element applications, as shown below.

\section{Finite element calculations}

State of the art in geotechnical engineering are calculations of stress and strain fields with finite element approaches. Commercial finite element programs often allow assessment of stability by means of so-called strength reduction analyses ( $\varphi-c$ reduction). A frequently used approach to assess stability is to reduce the shear parameters until loss of convergence in the numeric calculation. This approach is ambiguous, as convergence depends not only on the stability but also on numerical issues as, e.g. incrementation. Investigations on the occurrence of $\operatorname{tr}(\dot{\mathbf{T} D}) \leq 0$ in finite element calculations could give a more clear identification of instability [17, 22, 25, 27]. The here presented finite element calculations have been performed using Abaqus. For Abaqus, a user subroutine UmAt for the material model barodesy is available [31]. As barodesy is not formulated in the framework of elasto-plasticity, a special strength reduction approach has been developed [32]. Second-order work has been made available as additional output variable in the user material subroutine. Thus, second-order work can be visualized easily in the abaqus framework for barodesy.

Note that in the finite element applications addressed here, $W_{2}$ is evaluated with the actual $\dot{\mathbf{T}}$ and $\mathbf{D}$ tensors. In other words, a search for the D-tensor that minimizes $W_{2}$ has not been carried out, as it would render the calculations extremely lengthy. Consequently, the condition $W_{2}=0$ could be encountered even earlier. An analytical solution for the $W_{2}$ surfaces in stress space as developed by Niemunis [28] for hypoplasticity and applied by Meier et al. [22] is not yet archived for barodesy. However, the so obtained instability is still useful as indicator of failure.

\subsection{Biaxial tests}

The capability of modelling shear bands is an important property of material models. A first approach of visualizing shear bands in finite element calculations can be done on fine-meshed biaxial tests [14]. Finite element calculations of biaxial tests with barodesy have already been performed by Schneider-Muntau et al. [31], and the appearance of shear bands has been discussed. The same example is used in this article for shear band visualization with the secondorder work criterion. For a biaxial test with a homogeneous void ratio distribution over 200 elements $\left(e_{\text {ini }}=0.55\right)$, all elements have the same deformation, see Fig. 6 for the stress-strain relationship and Fig. 7 for the second-order work distribution. Second-order work vanishes for all elements at the same calculation step, which corresponds to the peak at an axial strain of $\varepsilon_{1}=6.7 \%$. Note that in laboratory tests inhomogeneous deformation exists from the very beginning of the test, be it small or pronounced.

As to be expected, biaxial tests with an imperfection (a single looser element with $e_{\text {ini }}=0.57$ ) show an inhomogeneous deformation from the very beginning of the test. In Fig. $6 \mathrm{~b}$, the stress-strain relationship of every single element is displayed. A similar behaviour for all elements is obtained until the peak. With continued deformation, the stress-strain relationships of each element get chaotic. At the peak, second-order work becomes negative for some elements. As can be seen in Fig. 8a, those elements form a 

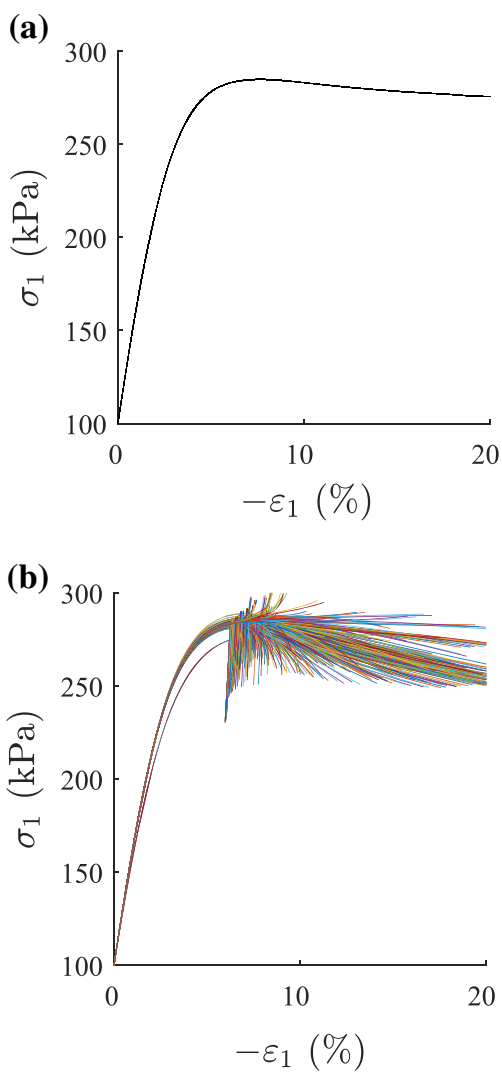

Fig. 6 Axial stress $\sigma_{1}$-axial strain $\varepsilon_{1}$ relationship of all 200 elements of a biaxial test: in a the void ratio distribution is homogeneous, in b the void ratio distribution is inhomogeneous (one weak element)

band of vanishing/negative second-order work. Note that dead load controlled deformation would not be possible at this stage any more. The first occurrence of a continuous shearband is at $6.7 \%$ axial strain, which corresponds to the peak of the homogeneous void ratio distribution. At this stage, the shear band is not visible in the void ratio distribution, Fig. 8b, and can only be guessed in the distribution of deviatoric strains, see Fig. 8c. Visualizing shear bands in terms of deviatoric strain or void ratio distribution only indicate strain accumulation and are dependent on the visualization scale.

\subsection{Slope stability}

Slope stability analyses in the framework of elasto-plasticity have been carried out, in order to identify unstable situations [4, 16, 27, 30]. Meier et al. [22] determine unstable areas of shallow slopes on the basis of a hypoplastic second-order work stability criterion according to Niemunis [28]. Slope stability finite element calculations with a strength reduction method for barodesy have been presented by Muntau et al. [32]. The material parameters $\varphi_{\mathrm{c}}$ (critical friction angle) and $N$ (ordinate intercept of the NCL) have been reduced gradually until the appearance of
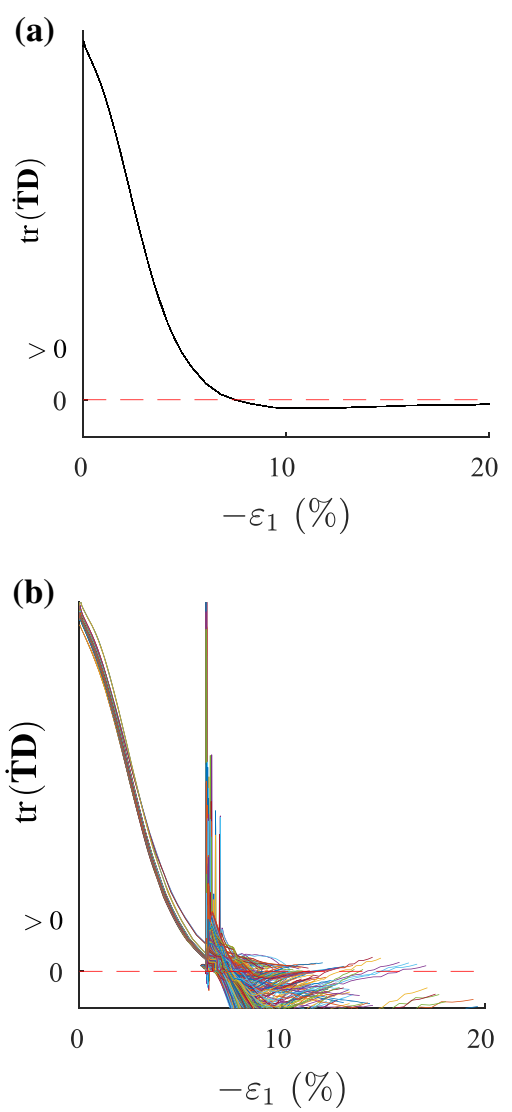

Fig. 7 Second-order work evolution of all 200 elements of a biaxial test: in a the void ratio distribution is homogeneous, in $\mathbf{b}$ the void ratio distribution is inhomogeneous (one weak element)

shear bands. The initial void ratio was set to 0.5 in all elements. Evaluating the shear band in terms of secondorder work $\leq 0$ yields the hatched areas in Fig. 9a. The band of vanishing/negative second-order work from bottom to top of the slope is clearly visible, contrary to the shear band in terms of void ratio distribution in Fig. 9b.

\section{Conclusions}

Vanishing second-order work appears to be an suitable criterion for a situation where failure may occur. To evaluate $\operatorname{tr}(\dot{\mathbf{T} D})$, all possible $\mathbf{D}$-tensors and the pertinent $\dot{\mathbf{T}}$ tensors (resulting from a particular constitutive relation) should be investigated. This search is time-consuming and has been applied for the element tests in Figs. 3, 4 and 5: we varied the stretching tensor in the deviatoric plane in order to search for minimum values of second-order work. As soon as second-order work vanishes, the investigated stress state belongs to the searched boundary. For a constant overconsolidation ratio, vanishing second-order work is described by a cone. For normally consolidated to 
(a)

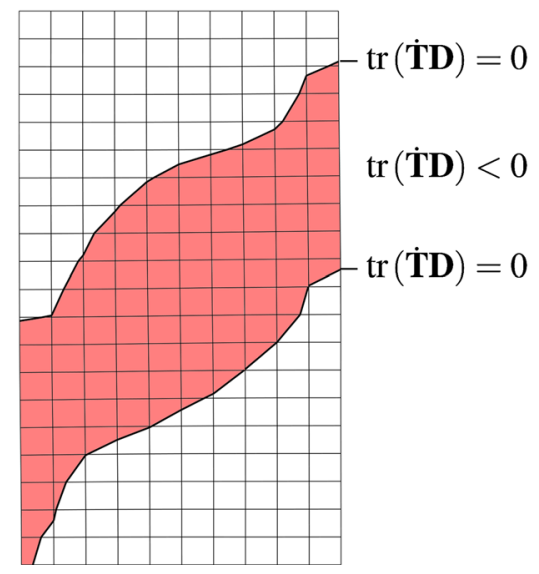

(b)

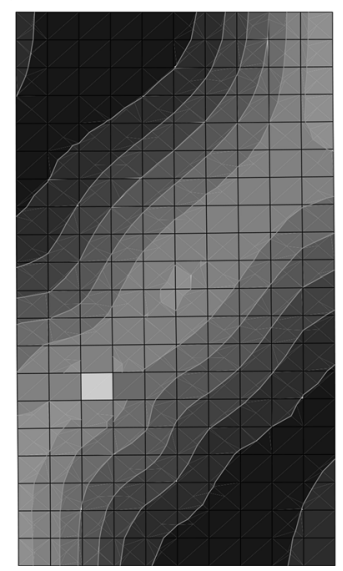

(c)

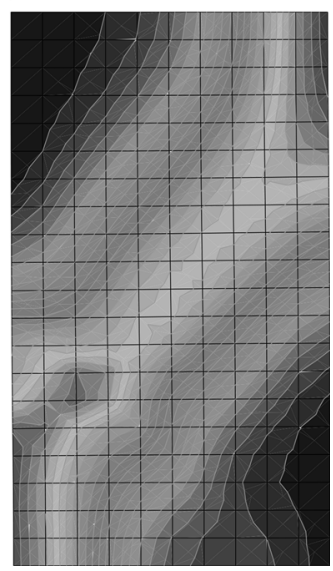

Fig. 8 Biaxial test at a vertical strain $\varepsilon_{1}=6.7 \%$ (peak), shearband visualization: In a areas are marked where second-order work $\leq 0$, b the void ratio distribution, in the range from 0.549 (black) to 0.561 (light grey), $\mathbf{c}$ the deviatoric strain, range from 0.07 (black) to 0.09 (light grey)
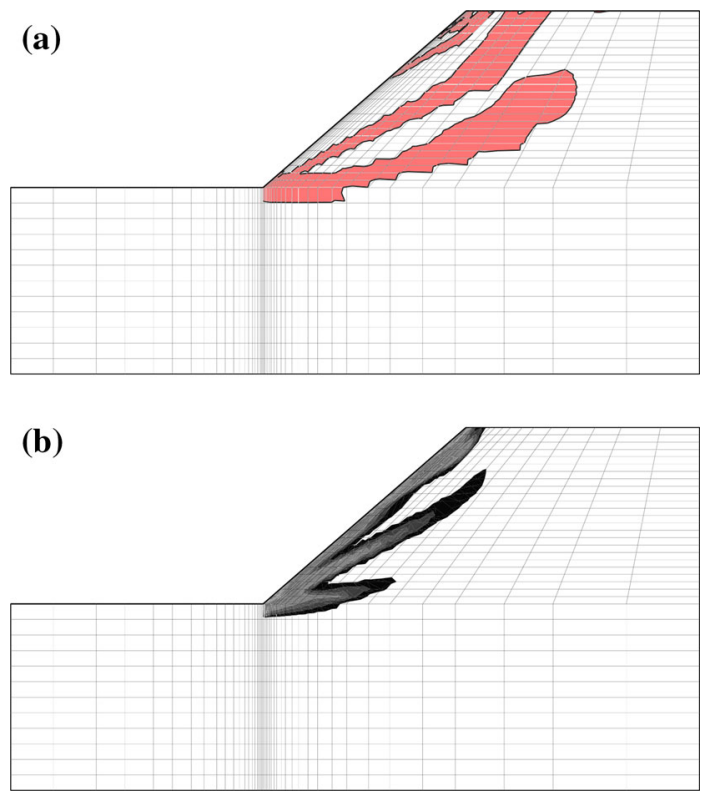

Fig. 9 Slope at the moment of an appearance of a visible shear band by means of negative second-order work. In a areas are marked where second-order work $\leq 0$ b shows the void ratio distribution which ranges from 0.55 (black) to 0.99 (light grey), areas in white are below 0.55

slightly overconsolidated soil, these cones lie inside the cone of critical stress states.

In barodesy, the second-order work approach showedlike in hypoplasticity and elasto-plasticity-that secondorder may vanish at stress states inside the critical limit surface. It is obtained that for rather loose soils, secondorder work vanishes inside the critical stress surface. Evaluating $W_{2}=0$ in the non-conventional triaxial tests in Fig. 2 with the actual $\mathbf{D}$-tensor and with a variation of $\mathbf{D}$, almost led to the same results for mobilized friction angles.
For finite element calculations, the variation of $\mathbf{D}$ is not feasible, so second-order work has been evaluated with the D-tensor which is obtained from the equations of motion. For boundary value problems, an end-to-end band of vanishing second-order work marks the state where failure is imminent. In this article, second-order work has been investigated for the following boundary value problems:

(1) Strain-controlled drained biaxial test with an initial imperfection (a slightly higher void ratio in one element). The stress-strain behaviour is similar for all elements until the peak, but then gets chaotic. At a certain strain-corresponding to the strain at the peak of a homogeneous sample-an area of vanishing or negative second-order work appears forming an end-to-end shear band.

(2) Slope stability has been investigated by means of second-order work. The first appearance of an endto-end band of $W_{2} \leq 0$ can define system failure.

Acknowledgements Open access funding provided by Austrian Science Fund (FWF). Gertraud Medicus is grateful for the financial support by a research Grant of the Austrian Science Fund (FWF): P 28934-N32. The authors thank Wolfgang Fellin for valuable discussion.

Open Access This article is distributed under the terms of the Creative Commons Attribution 4.0 International License (http://creative commons.org/licenses/by/4.0/), which permits unrestricted use, distribution, and reproduction in any medium, provided you give appropriate credit to the original author(s) and the source, provide a link to the Creative Commons license, and indicate if changes were made.

\section{Appendix 1: Equations of barodesy}

In this appendix, all equations of barodesy for clay [20] are summarized. 


$$
\begin{aligned}
& \stackrel{\circ}{\mathbf{T}}=h \cdot\left(f \mathbf{R}^{0}+g \mathbf{T}^{0}\right) \cdot|\mathbf{D}| \\
& \mathbf{R}=-\exp \left(\alpha \mathbf{D}^{0}\right) \quad \text { with } \quad \alpha=\frac{\ln K}{\sqrt{3 / 2-\operatorname{tr} \mathbf{D}^{0^{2}} / 2}} \\
& K=1-\frac{1}{1+c_{1}\left(m-c_{2}\right)^{2}} \quad \text { with } \quad m=\frac{-3 \operatorname{tr} \mathbf{D}^{0}}{\sqrt{6-2 \operatorname{trD}^{0^{2}}}} \\
& h=c_{3}|\mathbf{T}|^{c_{4}} \\
& f=c_{6} \cdot \beta \cdot \operatorname{tr} \mathbf{D}^{0}-\frac{1}{2} \\
& g=\left(1-c_{6}\right) \cdot \beta \cdot \operatorname{tr} \mathbf{D}^{0}+\left(\frac{1+e}{1+e_{\mathrm{c}}}\right)^{c_{5}}-\frac{1}{2} \\
& e_{\mathrm{c}}=\exp \left(N-\lambda^{*} \ln \frac{-2 / 3 \operatorname{tr} \mathbf{T}}{\sigma^{*}}\right)-1 \\
& \beta=-\frac{1}{c_{3} \Lambda}+\frac{1}{\sqrt{3}} 2^{c_{5} \lambda^{*}}-\frac{1}{\sqrt{3}} \\
& \Lambda=-\frac{\lambda^{*}-\kappa^{*}}{2 \sqrt{3}} \operatorname{tr} \mathbf{D}^{0}+\frac{\lambda^{*}+\kappa^{*}}{2}
\end{aligned}
$$

(a)
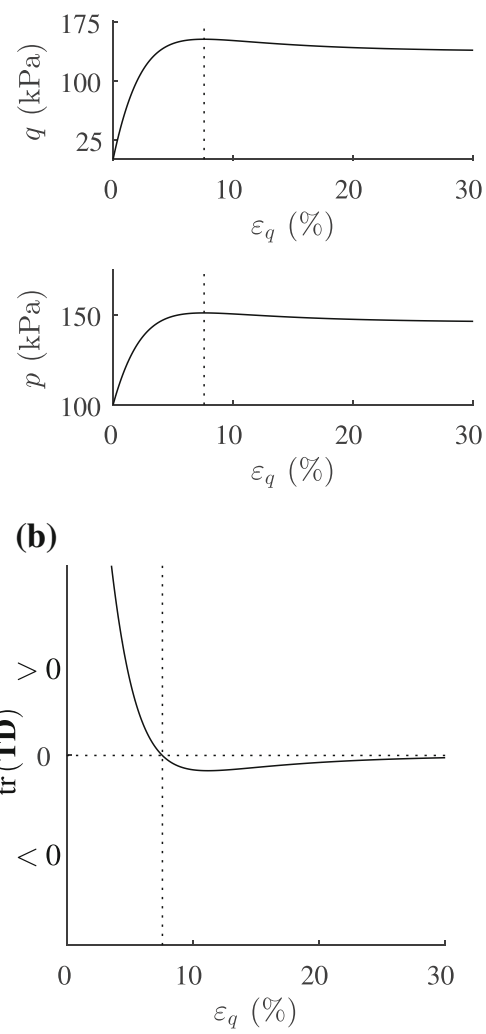

Fig. $10 \mathrm{~A}$ drained triaxial test $\left(e_{\text {ini }}=0.55\right.$ and $\left.p_{\text {ini }}=100 \mathrm{kPa}\right)$ of Weald clay is simulated with barodesy. $W_{2}=0$ when $\dot{q}=\dot{p}=0$. In a mean stress and deviatoric stress are plotted versus deviatoric strain, in $\mathbf{b}$ second-order work is plotted versus the deviatoric strain $\varepsilon_{q}$
The constants $c_{1}-c_{6}$ can be determined on the basis of the critical state soil mechanics parameters $\varphi_{\mathrm{c}}, N, \lambda^{*}$ and $\kappa^{*}$, cf. [20].

\section{Appendix 2: Drained triaxial test}

For axisymmetric loading conditions, Eq. 2 can be rewritten as:

$$
\operatorname{tr}(\dot{\mathbf{T D}})=\dot{T}_{1} \cdot \dot{\varepsilon}_{1}+2 \cdot \dot{T}_{2} \cdot \dot{\varepsilon}_{2}=-\dot{p} \cdot \dot{\varepsilon}_{\mathrm{vol}}-\dot{q} \cdot \dot{\varepsilon}_{q}
$$

In the peak state of a drained triaxial test, we have $\dot{p}=\dot{q}=0$. Thus, at the peak $\left(\varphi_{\mathrm{m}}=25.65^{\circ}\right)$ of a drained triaxial test, second-order work vanishes, cf. Fig. 10. A variation of $\mathbf{D}$ according to Eqs. 21-23 in order to find vanishing values of $W_{2}$ results in a slightly lower mobilized friction angle of $\varphi_{W_{2}}=25.57^{\circ}$. The critical friction angle of Weald clay is $24^{\circ}$. It is interesting to investigate whether the condition $\operatorname{tr}(\dot{\mathbf{T} D})=0$ can be encountered even before the peak. This is in fact the case with conventional triaxial tests [11] and can be experimentally shown with so-called non-conventional drained triaxial tests, cf. Sect. 4.2.

\section{References}

1. Arthur JRF, Dunstan T, Al-Ani QAJL, Assadi A (1977) Plastic deformation and failure in granular media. Géotechnique 27(1):53-74. https://doi.org/10.1680/geot.1977.27.1.53

2. Chambon R (2005) Some theoretical results about second-order work, uniqueness, existence and controllability independent of the constitutive equation. J Eng Math 52(1):53-61. https://doi. org/10.1007/BF02694030

3. Daouadji A, Darve F, Al Gali H, Hicher PY, Laouafa F, Lignon S, Nicot F, Nova R, Pinheiro M, Prunier F, Sibille L, Wan R (2011) Diffuse failure in geomaterials: experiments, theory and modelling. Int $\mathrm{J}$ Numer Anal Methods Geomech 35(16):1731-1773. https://doi.org/10.1002/nag.975

4. Darve F, Laouafa F (2000) Instabilities in granular materials and application to landslides. Mech Cohesive-Frict Mater 5(8):627-652. https://doi.org/10.1002/1099-1484(200011)5:8< 627::AID-CFM109>3.0.CO;2-F

5. Fellin W, Ostermann A (2013) The critical state behaviour of barodesy compared with the Matsuoka-Nakai failure criterion. Int J Numer Anal Methods Geomech 37(3):299-308. https://doi. org/10.1002/nag.1111

6. Gasparre A (2005) Advanced laboratory characterisation of London clay. Ph.D. thesis, Imperial College of Science and Technology, London

7. Herle I, Kolymbas D (2001) Pressure- and density-dependent bifurcation of soils. In: Mühlhaus HB, Dyskin AV, Pasternak EV (eds) Bifurcation and localisation theory in geomechanics. Balkema, Perth, pp 53-58

8. Herle I, Nitzsche K (2012) Prognose von aushubbedingten Baugrundverformungen. In: 16. Dresdner Baustatik-Seminar

9. Hill R (1957) On uniqueness and stability in the theory of finite elastic strain. J Mech Phys Solids 5(4):229-241. https://doi.org/ 10.1016/0022-5096(57)90016-9 
10. Kakogiannou E, Sanavia L, Nicot F, Darve F, Schrefler BA (2016) A porous media finite element approach for soil instability including the second-order work criterion. Acta Geotech 11(4):805-825. https://doi.org/10.1007/s11440-016-0473-5

11. Kolymbas D (1981) Bifurcation analysis for sand samples with a non-linear constitutive equation. Ingenieur-Archiv 50(2):131-140. https://doi.org/10.1007/BF00539697

12. Kolymbas D (2009) Sand as an archetypical natural solid. In: Kolymbas D, Viggiani G (eds) Mechanics of natural solids. Springer, Berlin, pp 1-26

13. Kolymbas D (2015) Introduction to barodesy. Géotechnique 65(13):52-65. https://doi.org/10.1680/geot.14.P.151

14. Kolymbas D, Rombach G (1989) Shear band formation in generalized hypoelasticity. Ingenieur-Archiv 59(3):177-186. https:// doi.org/10.1007/BF00532248

15. Lade P (1994) Instability and liquefaction of granular materials. Comput Geotech 16(2):123-151. https://doi.org/10.1016/0266352X(94)90018-3

16. Laouafa F, Darve F (2002) Modelling of slope failure by a material instability mechanism. Comput Geotech 29(4):301-325. https://doi.org/10.1016/S0266-352X(01)00030-1

17. Laouafa F, Prunier F, Daouadji A, Gali HA, Darve F (2011) Stability in geomechanics, experimental and numerical analyses. Int J Numer Anal Methods Geomech 35(2):112-139. https://doi. org/10.1002/nag.996

18. Mašín D (2005) A hypoplastic constitutive model for clays. Int J Numer Anal Methods Geomech 29(4):311-336

19. Mašín D (2013) Clay hypoplasticity with explicitly defined asymptotic states. Acta Geotech 8(5):481-496. https://doi.org/10. 1007/s11440-012-0199-y

20. Medicus G, Fellin W (2017) An improved version of barodesy for clay. Acta Geotech 12(2):365-376. https://doi.org/10.1007/ s11440-016-0458-4

21. Medicus G, Kolymbas D, Fellin W (2016) Proportional stress and strain paths in barodesy. Int J Numer Anal Methods Geomech 40(4):509-522. https://doi.org/10.1002/nag.2413

22. Meier T, von Wolffersdorff PA, Tamáskovics N (2017) Neuartiger Standsicherheitsnachweis für verflüssigungsgefährdete Kippen. In: Fachsektionstage Geotechnik, Deutsche Gesellschaft für Geotechnik (DGGT), pp 466-471

23. Muir Wood D (2004) Geotechnical modelling. Spon Press, London

24. Nakai T (2007) Modeling of soil behavior based on $t_{i j}$ concept. In: Proceedings of 13th ARCSMGE, Kolkata, vol 2, pp 69-89, keynote Paper
25. Nicot F, Darve F (2015) Describing failure in geomaterials using second-order work approach. Water Sci Eng 8(2):89-95. https:// doi.org/10.1016/j.wse.2015.05.001

26. Nicot F, Daouadji A, Laouafa F, Darve F (2011) Second-order work, kinetic energy and diffuse failure in granular materials. Granul Matter 13(1):19-28. https://doi.org/10.1007/s10035-0100219-2

27. Nicot F, Lerbet J, Darve F (2017) Second-order work criterion: from material point to boundary value problems. Acta Mech 228:2483-2498. https://doi.org/10.1007/s00707-017-1844-1

28. Niemunis A (2003) Extended hypoplastic models for soils. No. 1 in Schriftenreihe des Institutes für Grundbau und Bodenmechanik der Ruhr-Universität Bochum, Habilitation Thesis

29. Nova R (1994) Controllability of the incremental response of soil specimens subjected to arbitrary loading programmes. J Mech Behav Mater 5:193-202. https://doi.org/10.1515/JMBM.1994.5.2.193

30. Prunier F, Laouafa F, Lignon S, Darve F (2009) Bifurcation modeling in geomaterials: from the second-order work criterion to spectral analyses. Int $\mathbf{J}$ Numer Anal Methods Geomech 33(9):1169-1202. https://doi.org/10.1002/nag.762

31. Schneider-Muntau B, Chen CH, Bathaeian SMI (2017) Simulation of shear bands with Soft PARticle Code (SPARC) and FE. GEM Int J Geomath 8(1):135-151. https://doi.org/10.1007/ s13137-016-0091-2

32. Schneider-Muntau B, Medicus G, Fellin W (2018) Strength reduction method in barodesy. Comput Geotech 95:57-67. https://doi.org/10.1016/j.compgeo.2017.09.010

33. Vardoulakis I (1980) Shear band inclination and shear modulus of sand in biaxial tests. Int $\mathrm{J}$ Numer Anal Methods Geomech 4(2):103-119. https://doi.org/10.1002/nag.1610040202

34. Wan R, Pinheiro M (2009) Analysis of failure in geostructures via the second order work. In: 1st international symposium on computational geomechanics, COMGEO I, Juan-les-Pins, France

35. Wan R, Pinheiro M, Daouadji A, Jrad M, Darve F (2013) Diffuse instabilities with transition to localization in loose granular materials. Int $\mathrm{J}$ Numer Anal Methods Geomech 37(10):1292-1311. https://doi.org/10.1002/nag.2085

Publisher's Note Springer Nature remains neutral with regard to jurisdictional claims in published maps and institutional affiliations. 